\title{
Experiences of Stakeholders on the School Counselling Services in Ohangwena Region of Namibia
}

\author{
Anna Niitembu Hako \\ Department of Educational Psychology \& Inclusive Education, \\ University Namibia \\ Olaniyi Bojuwoye \\ Department of Educational Psychology, \\ University of the Western Cape, South Africa
}

\begin{abstract}
This is an interpretive account of principals, teacher-counsellors, parents and learners' experiences and perceptions on school counselling services in Ohangwena region of Namibia. The study focused on what the stakeholders consider to be the characteristics of the Namibian school counselling programme. The study used a qualitative research approach to collect data. The sample consisted of fifteen learners, twelve teachercounsellors, three parents and five school principals who were purposively selected. Interviews (in-depth semi-structured) and focus group discussions were used to gather data. The results revealed that participants consider counselling, academic development, career planning, education and/ or information dissemination, consultation and referral as the major services that characterize the Namibian School Counselling Programme. While the study highlighted the strengths of the Namibian School Counselling Programme, recommendations are also made regarding areas of the programme which can be improved.
\end{abstract}

Keywords: School-counselling services, School guidance, Stakeholders, Perceptions, Learners, Parents, Teacher-counsellors.

\section{Background and context}

Three fields, namely: vocational guidance, the testing movement and the mental health movement have influenced the school guidance movement. The gradual integration of these areas has resulted in the school counselling profession, as it is known today (Stone \& Bradley, 1994). Early in the twentieth century, the first organised public school guidance programme was 
initiated in the United States of America. It has since expanded to other countries in the world including Namibia.

South West Africa (SWA), as Namibia was called before independence, was a Germany colony and then a mandated territory of South Africa until 1989. During that time, the education system was segregated along ethnic lines. Before Independence in 1990, there was no structured guidance and counselling services for the black children in the then South West Africa or they were exclusively for the whites and coloured schools. The development of guidance and counselling services reflected the same racial segregation in the whole education system of South West Africa. However, when Namibia gained Independence in 1990, the school counselling programme was expanded to cover all public schools to ensure that all Namibians have equal educational opportunities.

The school counselling programme in Namibia is under the auspices of the Programme Quality Assurance (PQA) division in the Ministry of Education, Arts and Culture. The counselling activities are coordinated under the umbrella of the Special Education Programmes sub-division by both School Counsellors from Head Office and Regional School Counsellors from each of the fourteen regions in the country.

Namibia experiences a growing number of social problems that affect the lives of young people. These problems include poverty, teenage pregnancy, peer pressure, domestic violence, unemployment, passion killings, HIV \& AIDS and alcohol and drug abuse (Ministry of Education, Management Information System, 2009). These problems are not, however, unique to Namibia, as there is also an increase in the divorce rate and in the number of single-parent families all over the world, which is also a stress factor for learners (Chireshe, 2011). Not only does the ever-increasing needs of children and the expectations of today's society impose growing demands on the education system, but also requires schools to find solutions and respond to these needs by providing counselling services to all learners to learn effectively (Mbongo, Möwes \& Chata, 2016).

The overall goal of the Namibian School Counselling Programme is the" total development” of learners. Lunenburg (2010) states that, it is crucial that schools create an environment conducive for teaching and learning so that every learner with an identifiable problem is cared for and supported to achieve his/her full potential and adjust well to life.

Although many studies have shed light on several counselling services offered in schools, (Mbongo, Möwes \& Chata, 2016; Mushaandja, Haihambo, Vergnani \& Frank, 2013; Talimethi \& Mbewa, 2012; Alemu, 2013; Chireshe, 2011; Gallant \& Zhao, 2011), there has been little evidence from a Namibian context. On this basis, the purpose of the study was to understand from the participants' perspective, the counselling services offered in Namibian schools 
and their effectiveness on enhancing students' self-knowledge and understanding. This study aims to contribute to the existing knowledge by documenting the programme's service characteristics that are contextsensitive or directed to meeting the needs of the learners. The findings of this study also have potential to assist policy-makers and school managers in strengthening the provision of counselling services in schools and the accessibility of these services to all in need.

\section{The study site context}

The study was conducted in Ohangwena region. The region borders Cunene Province in Angola to the north and Kavango, Oshikoto, Oshana and Omusati regions in Namibia.

Ohangwena region has the second highest number of schools (253) of which 7 are privately owned while 246 are state owned schools. In 2015 the region recorded the highest enrollment rate of 13.9 percent followed by Omusati region with 13.7 percent (Namibia Statistics Agency (NSA), 2015). It is further documented that this region is one of the poorest regions in Namibia, has the ninth worst literacy rate, but has the third highest gross school enrolment ratio. Recent analysis of results of Standardised Achievement Tests (SATs) show that in Ohangwena region, 70\% of Grade 5 learners were graded as "below basic achievement" (meaning the learner demonstrated insufficient knowledge and skills across all themes in the syllabus) in English compared to 21\% in Khomas and 52\% in Otjozondjupa (Ninnes, 2011).

\section{Literature review}

Various scholars have identified counselling services that characterize the school counselling programme (Borders \& Drury, 1992; Gibson \& Mitchell, 2008; Lapan, Gysbers \& Sun, 1997; Gysbers \& Henderson, 2001; Myrick, 2003; Gysbers, Lapan \& Petroski, 2001; Schmidt, 2003; ASCA, 2003). The general consensus among academics is that both indirect and direct services are characteristics of the school counselling programme and these are frequently categorized as counselling and classroom guidance (direct services), consultation and coordination (indirect services). According to results of various studies (Gibson \& Mitchell, 2008; Lapan, Gysbers, \& Sun, 1997; Myrick, 2003; Gysbers, Lapan \& Petroski, 2001; Schmidt, 2003; Chata \& Loesch, 2007), practicing counsellors, their learners, teachers, principals and parents, endorse these services.

The study by Schimmel (2008) revealed that teacher-counsellors were engaged in tasks related to the foundation, management and delivery of accountability aspects of the comprehensive school counselling programme as outlined in the America School Counsellor Association, ASCA, (2003). The 
majority of school counsellors involved in the study strongly felt that they were engaged in two main tasks related to the main components of the comprehensive programme including that school counsellors regularly consult with parents, teachers and principals, and that teacher-counsellors counsel learners individually about personal-social issues.

Bardhoshi and Duncan (2009); Frank (1986) and Kuhn (2004) found that items falling under the Responsive Services category rated as most or of highest importance, especially items related to Guidance Curriculum, System Support and Individual Student Planning. Under the School Guidance Curriculum category, the items rated were academic support, study and test taking skills, peer relationships, coping strategies and effective social skills. The least rated service was professional development. In the Individual Student Planning category, all respondents rated education on understanding of self, including understanding the individual personal strengths and weaknesses, and academic planning as important or very important.

These findings contradicted those of Pérusse, Goodnough, Donegan and Jones (2004) and Ross and Herrington (2006) who found that elementary school principals rated administering cognitive, aptitude, and achievement tests, maintaining learners' records, and registration and scheduling of new learners as appropriate counselling activities. More than $80 \%$ of the secondary school principals studied rated registration and scheduling of new learners, administering cognitive, aptitude and achievement tests, and maintaining learners' records as appropriate school counsellors' activities in that descending order of importance.

Zalaquett's (2005) study found that counsellors argued repeatedly that non-counselling activities have a detrimental effect on their capability to offer relevant services to their learners and have criticized principals for assigning them non-counselling administrative tasks. This type of finding is of interest to the current study as the study was designed to ascertain the different stakeholders' views of the services (administrative or otherwise) that characterize the Namibian school counselling programme.

\section{Methodology}

\section{Research design and approach}

The study adopted a case study design framed within a qualitative research approach which facilitated an exploration study in order to gain insight into the participants' comprehension of the phenomenon investigated (Babbie \& Mouton, 2001). The qualitative approach helps researchers to describe and interpret participants' perceptions, attitudes, beliefs, and feelings relevant to their experiences of school counselling services received and used for improving the quality of students' learning. Data gathering involves interactions among participants permitting the qualification of ideas, values, 
and meaning through the eyes of the participants than quantification through the eyes of outside observers (Neuman, 2011).

\section{Participants}

The stakeholders, including school principals, teacher-counsellors, parents and learners from Ohangwena Directorate of Education constituted the population for the study.

Learners being the primary beneficiaries of the school counselling programme were in the best position to provide relevant information on their school counselling programme. Teacher-counsellors being the implementers of the counselling programmes in schools were the best to know all the challenges facing the implementation of such programmes. Principals are the managers of the institutions where school counselling programmes are being implemented and services to address barriers to learning offered. The principals therefore were in the best position to offer evaluative information particularly about the services required to fulfil the objectives of the programme. In addition, parents are key stakeholders regarding the effectiveness of school couselling services provided to their children as many principals give considerable weight to parental input.

\section{Sample and sampling methods}

The sample of participants for this study comprised of twelve learners, five males and eight females. Their ages ranged between 10 to 19 years of age and were in grades 5 to 10 .

There were also twelve teacher-counsellors, five males and seven females. Their age ranged between 22 to 35 years of age. Seven of them have more than five years teaching experience while five of them have three years of teaching experience. All teacher-counsellors have a Bachelor of Education degree. The other participants were school principals, two females and one male. Their ages ranged between 40 to 52 years of age. All principals have teaching qualifications and work experience of more than 10 years. Two parents were females and one was male. All have served on the school governing body for more than five years.

Purposive sampling method was employed to select participants. The selection of participants was performed under a set of strict restrictions in order to obtain, not only relevant, but also significant results. All participants were therefore required to have experience on the school counselling services offered in schools. This means that, all participants one way or another, were involved in counselling activities prior to their participation in the study. For example, school principals were selected on the basis that they have been in that position for three consecutive years and that a school counselling programme is implemented at their respective schools. Learners, being the 
beneficiaries of the counselling services, were required to have gone through the counselling programme and that they receive Life skills education. Teacher-counsellors as the primary implementers of the counselling services were sampled because they have undergone the Basic Counselling skills, Bereavement Counselling and Process of Counselling training prior to the study. In addition, they should have, at one-point referred learners from their schools to Regional School Counsellors. In the case of parents, they were selected based on the requirement that they have served for five or more years on the school governing body. Thus, the researcher selected these key informants based on their experience and knowledge of the school counselling services and their willingness to participate in the study. The purposive sampling technique was used based on Bertram and Christiansen (2015) who advised that when choosing a sampling technique and a sample itself, researchers need to remember to select participants who can best add to the understanding of the phenomenon under study.

\section{Data collection methods and Instruments}

The study used focus groups and individual interviews in the data generation process. Focus group interviews are good for gathering rich data through direct interactions between researcher and participants and it is relatively inexpensive and effective with groups of lower literacy levels especially for parents with English as a second language as were the participants involved in this study. The individual interview method also allowed the researcher to obtain useful information as it explores and probes participants' responses to gather in-depth data about their experiences and feelings (Creswell, 2009). Principals, teacher-counsellors and learners' interviews were conducted in English at their respective schools in the afternoon to avoid lesson disruptions. However, the interviews for parents were conducted in a vernacular language (Oshiwambo) and then later transcribed verbatim due to their limited official language literacy levels. Focus groups and individual interviews lasted for between 30 to 45 minutes and were recorded and transcribed. All interview guides were developed to ensure that none of the important issues to be discussed is left out of the conversation.

The focus group discussions guide to which learners and teachercounsellors responded to covered the following questions: Could you please share with me, the types of counselling services that are offered at your school? Do you have personal experience in regard to counselling? Could you please share your experience? How is your experience similar to or different from others? How do you get access to career information at school? How do other stakeholders get involved in helping you if you have concerns/ problems at school? What happens to you if you have a problem that your Teacher- 
counsellor cannot handle? Do you have any other information related to counselling services that were not covered in this interview?

Similarly, the individual interview questions with parents and principals were more or less the same with the focus group discussion questions. For example, participants were also asked to share with the researcher the types of counselling services offered at that particular school. What is your opinion about the counselling services offered at this school? How is your opinion similar or different from others? What are the other services available in the community for learners? How do other service providers come on board to help learners who are having problems? How do learners get information about career education? What happens to learners if they encounter problems at school? Who else is available in the community to help learners in need? Do you have any other information related to counselling services that were not covered in this interview?

\section{Procedures for data collection}

Before collecting data, the researcher submitted a research proposal for the present study to the Senate Research Ethics Committee of the University of the Western Cape and obtained an ethical clearance certificate with the registration number 11/9/32. Further, the researcher sought permission from the Ministry of Education, Arts and Culture to conduct a research. Permission to conduct the study in the selected schools in Ohangwena region was also sought from the Director of Ohangwena Directorate of Education. In each school involved in the study and with the assistance of the school principal, participants were informed of the purpose of the study and the conditions for participation both orally and in writing in groups within the school premises. In addition, the researcher obtained signed informed consent forms from each participant who participated in the individual one-on-one and focus group interviews. For instance, prior to participation, respondents were assured of their anonymity, the confidentiality of information they were to give as well as the voluntary consent to electronic recording of interviews, nature of their participation and the fact that, if they so wish, they could withdraw at any time from the study. Information in this regard and about the study in general, was contained in the informed consent form each participant signed before participating in the study.

\section{Methods of data analysis}

Data were processed using thematic analysis, which refers to identifying, analyzing and reporting patterns or themes across the data (Neuman, 2011). This involves several steps, namely: becoming familiar with the data by repeated reading of the transcripts, developing initial codes through line-by-line analysis of all statements that referred to participants' experiences 
of school counselling services, searching for "patterned responses" among the initial codes and grouping them into themes that speak to the phenomenon of school counselling services, (e.g. identifying repetitions in content both within and across the interviews), and developing superordinate themes by looking for interconnections and overlaps among the themes (Bertram \& Christiansen, 2015).

\section{Findings}

The results are presented below in the form of themes that emerged, with supporting quotations from focus group discussions and interviews' transcriptions.

Participants reported on a range of services offered under the Namibian school counselling programme that help learners to solve problems, make decisions, develop responsible healthy behaviours, attitudes and values and reduce learning problems. The services participants reported are counselling, information dissemination and or education, consultation (with teachers and parents), career development, curriculum support and academic skills development, orientation, referral and a number of other non-educational services.

\section{Counselling services}

\section{Learners}

When responding to a question on what they perceived as counselling services of the Namibian school counselling programme, learners reported that teacher-counsellors in Namibian schools often engage with learners, parents and teachers on an individual one-on-one basis, either as in personal counselling, or on a small group basis (family group) in an attempt to address various problem situations.

One student stated that:

"we come together as a group and teachers or nurses advise us to stay away from alcohol and drugs" [ learner3].

Another student said:

"we do have AIDS Awareness club where we meet as a group and do poems and songs[learner 8]

\section{Teacher-counsellors}

On the question of counselling services of the Namibian schoolcounselling programme, teacher-counsellors highlighted that Window of Hope programme is also part of the counselling services as learners are exposed to various kinds of skills that they need to live a successful life. They felt that, by being taught Life skills as a subject in school, learners are being 
empowered with knowledge and skills to effectively face diverse challenges in life.

One teacher-counsellor said:

"Window of Hope club also contributed and I regard it also as an activity of counsellor.[TC1]

The other one claimed that:

"the service which a Teacher-counsellor offers at school is just a counselling and teaching Life Skills subject[TC3]

\section{Principals}

Principals' responses regarding the counselling activities or services of the Namibian school-counselling programme included the view that learners are being grouped in small groups and motivated to be free and open to their teachers when they encounter problems. During guidance activities in the classroom, learners also practiced assertive behavior skills to enable them to boldly face life issues.

One principal said:

"so, we normally used to have the meetings every month for counselling where learners need to be motivated, to be disciplined and to be open to come to the Teacher-counsellor whenever they have got problems, either at school, or at home with teachers or perhaps with other support staff at school "[principal $1]$.

The other one added that:

" exchange of views in guidance activities.......practice assertive behaviours in role plays" [principal 2]

\section{Parents}

Parents' responses regarding what they perceived as counselling services of the Namibian school counselling programme included the view that learners performed certain types of dramas from various plays. Additionally, girls clubs are established where they discuss about reproductive health issues and all these are part of counselling services offered at school.

One parent indicated that:

"I remember that children do drama, certain types of dramas and various plays" [parent ]

Another parent said:

“... girls clubs initiated at school....female learners reported about getting information on reproductive health issues" [parent 4]

The other parent added that:

......"motivational talks.....education campaigns on the prevention of violence in school"'[parent 2] 
Based on the participants' responses on school counselling services, one can conclude that they have the knowledge about the existence of the counselling services in schools, though they have different views and understanding on what specific activities the counselling program should comprise.

\section{Career Planning Services}

\section{Learners}

Learners' responses describing career-planning services of the Namibian school counselling programme revealed that every year, teachercounsellors organised trips to the Youth Centers so that learners can meet officials from different organizations who share information on career opportunities available in the country and abroad. Learners indicated that this is an opportunity for them to know what careers to follow in the future and what specific requirements are there in terms of subject choices and prerequisite courses.

One student stated that:

"...guidance education and career orientation that took place at schools; for instance, Career Fair where we are exposed to various career opportunities"[learner 5]

The other student added that:

"create a "Me and MY job" booklet...with learning about personal interests and responsibilities" [learner 7]

\section{Teacher-counsellors}

Teacher-counsellors' responses regarding career planning services of the Namibian school counselling programme are that Regional School Counsellors visit schools with other officials from line ministries to give talks and to motivate learners to study hard and choose appropriate subjects. During these visits, learners come into face-to-face contact with experts in various fields of study and thus create a better opportunity for them to learn from people with first-hand experience.

One teacher-counsellor said:

“....organize posters containing a list of the occupations they think women most commonly work in..." [TC 4]

The other one also added that:

“.......Regional career fairs are held every year for grade 10 and 12 learners" [TC 6]

\section{Principals}

Principals described the career planning services of the Namibian school counselling programme as sharing of career information with young people for them to choose better careers. Principals felt that career planning 
should start as early as possible so that leaners would not have problems in the future to decide on what career to follow. They indicated that it is very common nowadays to find learners in grade twelve who have no idea of the career they want to pursue once they complete grade twelve.

One principal stated that:

"displaying career information on the notice boards to expose learners to various careers available in the country" [principal 3]

Another added that:

"organize group meetings for presentation on the wide range post- secondary opportunities”[principal 2]

\section{Parents}

Parents' responses regarding career-planning services of the Namibian school counselling programme include engaging learners in discussions about the connection between education and career planning. Parents were also of the opinion that early exposure to career education will open opportunities for learners to advance in their career planning.

One parent said:

“.... arrange field trips to nearby business to help learners... [get first-hand experience] [parent 3]

The other one added that:

"...host school career day" [parent 5]

Concerning career planning services, participants reported on certain educational services (information and skills-based) of some non-governmental organizations which are coordinated by the Namibian school counselling programme. Some of these educational activities and or services include career fairs and field trips or career excursions organized to educate or provide information to learners on careers and further education opportunities.

\section{Education Services (Information-based services) Learners}

Concerning education services (Information-based services), learners highlighted that they receive information through various platforms, for example, girls and boys HIV clubs, Window of Hope clubs and other programmes that disseminate information on social and communication skills. Learners felt that through various clubs at school, they are empowered with social skills that enable them to work together with other learners and appreciate diversity, not only in terms of cultural backgrounds, but also in understanding life issues.

One learner stated that:

"there is HIV and AIDS awareness club there[where learners are given information or educated about HIV and AIDS]"[learner 8] 
The other learner added that:

"we do have Window of Hope (WoH) and My Future is My Choice (MFMC) programmes where we learned about social skills, and communication skills" [learner 9]

\section{Teacher-counsellors}

Teacher-counsellors' responses regarding education services indicated that they shared information with both learners and parents regarding HIV and AIDS and other diseases. They normally organise parent meetings and invite nurses and other knowledgeable people to address the parent-community at school. They also use Window of Hope and My Future is My Choice programmes to disseminate important information to leaners and other teachers.

One teacher-counsellor said:

"programmes such as Window of Hope, My Future is my Choice or Educational development on decision making" [TC 10]

Another one added that:

"we used to tell them [ learners] and inform them what is right and wrong and also to help them make informed decisions.[TC 4 ]

\section{Principals}

Principals described the education services of the Namibian school counselling programme as services where teacher-counsellors give relevant information to learners either thorough teaching Life Skills or life orientation subject or hosting information sessions at school. This service is not only important to learners, but also to teachers and parents. They felt that information is power.

One principal said:

"we have this My Future is My Choice program - which is now taught in the life skills session"[principal 2]

On this similar issue, the other principal added that:

... during immunization campaigns weeks, nurses address learners on the importance of being immunized" [principal 2]

\section{Parents}

Concerning education services, the parents' views are that it is of importance that teacher-counsellors make available to learners the latest information on a number of topics. They indicated that teacher-counsellors need to have resource materials in their offices, especially those which help learners in areas of educational information on how to study and information of a personal or social nature.

One parent said: 
"children said they are taught by teachers in the classrooms on how to behave and how to be in life and give them advice on how to choose relevant careers" [parent 3]

In the same vein, the other parent said:

"in that school counselling programme, activities Window of Hope" My Future is My Choice also provide information to learners [parent 1]

Participants reported on education and or information-based activities, which are conducted in workshops, talks, club meetings and even at school assembly that serve as avenues for information dissemination and teaching of life skills. Some of these services are also reported to be offered in schools by non-government organizations but coordinated by teacher-counsellors or Lifeskills teachers.

\section{Academic development services Learners}

In terms of academic development services, learners stated that they learn study skills, test taking skills and note taking skills during the guidance classroom activities. They felt that this academic development process assists them in learning and coping well with academic demands. However, some learners felt that sometimes information is too much for them to handle at once, as they do not have enough time to practice those skills during school time.

One learner said:

"we do exercise on test taking skills and effective listening skills"[learner 5] On the similar issue, the other learner said:

"teacher-counsellor organize after school hours meetings for us to discuss problem solving

skills" [learner 6]

Another one added that

" the school organize talks and bring former students to talk to learners about the values of education and the need to stay in school to complete", [ learner 3]

\section{Teacher- Counsellors}

On the question of academic development services, teachercounsellors emphasised the issue of organising meetings in small groups of learners to teach them how to apply study skills and all other important skills they need to succeed academically.

One teacher-counsellor said:

" teacher-counsellors organize discussions with learners to teach them how to develop and apply effective study skills"[TC 1]

The other one added that: 
...” teacher-counsellors organize clubs for learners to learn important skills as critical thinking, problem-solving skills, individual initiative skills\{TC 3]

\section{Principals}

About the academic development services, principals indicated that those are available for learners as teacher-counsellors organise seminars to help learners with how to take notes in class and discuss topics related to academic achievement.

One principal indicated that:

"Teacher-counsellors organise workshops to train learners in note taking skills and study skills[principal 2]

The other principals said:

“learners do brain teaser exercises to practice thinking skills"[principal 3] Another one also added that:

"Teacher- counsellors run a counselling group for learners on topics related to academic development and achievement" [principal 1]

\section{Parents}

Concerning academic development services, parents also indicated that the learners are exposed to study skills, examination taking techniques for them to overcome test anxiety.

One parent said:

“...they [learners] practice good examination skills and learn how to apply them when writing an examination" [parent 3]

The other parent shared that:

“..Teacher-counsellors educate learners on how to overcome test anxiety by demonstrating relaxation techniques"[parent 1

Participants considered the most important goal of the Namibian school counselling programme to be the development of academic skills in the learners. Therefore, given priority are special services which participants reported to be specifically organized to act as academic support and to help learners develop study skills, make notes, manage their time, prepare for examinations and to develop favorable attitudes and values for regular school attendance and to avoid failure in the school.

\section{Consultation Services}

\section{Learners}

When asked about the consultation services, learners responded that teacher-counsellors involve parents and other stakeholders in education by inviting them to come and address the learners on issues affecting their 
learning. Learners further indicated that parents are called to school to check their books and to see how their children are doing academically.

One learner said:

Teacher-counsellors organised parents' meetings to check our books" [ learner 10]

Another learner added that:

"organizations such as UNICEF and RED CROSS provided school uniforms, school bags, tents, and some materials to schools" [learner 6]

One also shard that

.....teacher-counsellors invite police officers to school and address learners on the danger crime activities"[learner 2]

\section{Teacher-counsellors}

In response to the question on consultation services, teachercounsellors indicated that they organise community meetings where they educate parents on several issues, including the importance of the family literacy programme that is targeting parents of grade one learners. In those meetings, parents are also enlightened on issues of how to deal with unruly children.

One parent said:

'Parents education sessions are organised to discuss learner' progress in school" [TC7]

Another parent said:

"[teacher-counsellors] consult with parents or guardians, other educators and community agencies on appropriate interventions and programmes for learners" [TC 4]

The other parent added that:

"organising groups of parents or other family members on how to deal best with learners-' developmental challenges" [TC 3]

\section{Principals}

On the issue of consultation, principals shared that teacher-counsellors collaborate with other service providers like Community Based Organizations (CBOs) such as Red Cross and UNICEF who help learners by providing schools with First Aid Kits and explain to learners the importance of healthy living or lifestyles. Principals had this to say.

" under the umbrella of school counselling services, we got nurses from nearby hospital to come and talk to our learners on health related issues, especially. on how to maintain good health" [principal 2]

“... through school counselling services discussion groups on behavioural interventions or curriculum planning with teacher-counsellors are held"[principal 3] 


\section{Parents}

Echoing school principals, parents emphasised that teachercounsellors consult with other local service providers; for instance, Regional Constituency Councillors and Red Cross officials to contribute materials and other essentials to schools to use for counselling activities, and also consult with social workers and nurses to effectively provide a comprehensive school counselling programme.

One parent said:

“...follow-up...with social workers on social grants applications Orphans and Vulnerable Children(OVCs) and investigate why acquiring national documents is a problem to many orphans..."[parent 1

Participants reported that teacher-counsellors consult with other service providers such as nurses (for health related issues) and Social Workers (for social welfare related matters such as grants and financial support for lowincome families). Participants further reported that due to the high prevalence of violence in schools, teacher-counsellors liaise with Police Officers to come to schools to address learners on alcohol and drug abuse. They further revealed that teacher-counsellors consult with community-based organizations, such as the RED CROSS, to help provide schools with the First Aid Kits and information on health-related issues and how to maintain good and healthy life styles to learners.

\section{Referral services}

\section{Learners}

On the question of referral services, learners indicated that when they encounter a problem or a crisis that a teacher-counsellor cannot handle, they are referred to other specialists in the area. There are many organizations and line ministries that teacher-counsellors refer learners to, depending on the case. For example, if it is a social issue, then learners are referred to Social Welfare offices to get help.

One learner said:

"we are sent to the Ministry of Gender Equality and Child Welfare to register for social grant support"[learner 9]

The other one added that:

...." parents are referred to social workers to secure social welfare services"[learner 5]

\section{Teacher-counsellors}

When responding to this question, teacher-counsellors highlighted that the availability of other service providers in the community makes it easy to refer learners. They specifically mentioned the Women and Child Protection 
Unit in the Ministry of Gender and Child Welfare that deals with all types of abuses, so any one can be referred there to get assistance.

Teacher-counsellors indicated that:

".... learners with severe behavioural disorders and emotionally disturbed are referred to private psychologist" [TC 8]

".... referrals for one-on-one counselling of learners may come from both teachers and learners [TC 3]

\section{Principals}

To this question, principals responded that learners and their families receive help through other programs and/or individuals in the school system as well as from community agencies outside the school. They added that Orphans and Vulnerable Children (OVCs) are normally referred to social workers for social grant services.

One principal said:

...."families are referred to social workers, especially, needy families to secure financial and

\section{Parents}

Parents reported that referral services include learners being referred to social workers for the acquisition of social grants. They showed appreciation for this service as most of the needy children are being taken care of with public funds, but all this is happening because parents were shown the right channels and procedures to follow in order to secure funds for their children.

One parent said:

...” teacher-counsellor initiates referrals to private agencies"[parent 2]

The other one added that:

" abused learners are referred to Women and Child Protection Unity in the Ministry of Gender and Child Welfare"[parent 1]

Participants indicated that, in order to work with ease, teachercounsellors make sure they maintain appropriate referral networks with personnel such as social workers, nurses and community agencies personnel to address some learners' issues. The reports by the participants also indicate that abused learners are referred to the Women and Child Protection Unit in the Ministry of Gender and Child Welfare.

\section{Discussion}

School counselling programme services refer to actions and activities carried out to actualize and make the school counselling programme operational in schools (Shertzer \& Stone, 1981). School counselling programme services are structured activities presented systematically through 
individual, classroom or group activities in order to achieve the objectives of the programme (Borders \& Drury, 1992; Gibson \& Mitchell, 1995; Lapan, Gysbers \& Sun, 1997; Gysbers \& Henderson, 2001; Myrick, 2003; Gysbers, Lapan \& Petroski, 2001; Schmidt, 2003; ASCA, 2005; Chata \& Loesch, 2007). School counselling programme has a broad range of activities and services for meeting the objectives of the programme such as assisting individual learners to understand themselves, their problems, their school environment and their world (Oniye \& Alawane, 2008; Gibson \& Mitchell, 1995; Lapan, Gysbers, \& Sun, 1997; Myrick, 2003; Gysbers, Lapan \& Petroski, 2001; Schmidt, 2003). These services are integral and essential components of the educational process for all learners as they progress through the educational systems.

The study found out that counselling, career planning, education and information dissemination, academic, consultation, and referral services were endorsed by the participants as being offered by the Namibian School Counselling Programme. These services are consistent with those described by Bardhoshi and Duncan, (2009); Frank, (1986) and Kuhn, (2004) as core services, which a school counselling programme, should provide, and these include counselling, consultation, planning and coordination. However, the study of Zalaquett (2005) and that of Ross and Herrington (2006) reported that when a counselling programme exists, teacher-counsellors are often asked to add administrative duties such as testing, supervising and class scheduling.

Included among services of school counselling programmes is a set of services described as responsive services that include individual and group counselling, crisis counselling, prevention and remediation services, consultation and referral. It is further contended that these services are essential for those students whose life challenges create barriers to classroom performance, academic success and healthy development in academic, career and personal/social arenas. Thus, as revealed in the contextual framework or the background introduction to this study, the Namibian environment with its disease burden of Human Immunodeficiency Virus (HIV) and poor socioeconomic conditions of the majority of its people, the kinds of services endorsed by the participants of this study are probably those with high probability of addressing the life challenges of the beneficiaries of the Namibian school counselling programme.

The study further revealed that teacher-counsellors invite community members with expertise to come and address learners on pertinent issues affecting their lives. Echoing this sentiment, Chata and Loesch (2007) believe that it is important that individuals from the community may be approached to talk to learners about issues such as HIV/AIDS, drug abuse, personal safety or specific careers. Since the main mission of any educator is to see his or her learners progressing and achieving academically by making efforts to free the 
learners from challenges and/or barriers to learning, this stance of the teachercounsellors and the principals certainly finds support in the statement by UNESCO (2008) that the goal of any school is to focus on addressing intellectual, emotional, social and psychological needs of learners by employment of counselling, academic support and career development services.

\section{Conclusion and limitations}

Study findings revealed that the Namibian school counselling programme provides a structured and systematic broad range of services targeting individual, classroom and groups that help to facilitate educational, emotional, social, career and overall personality development of learners. The programme is also very context-sensitive as it provides services to meet the socio-economic needs and helps to address a number of their life challenges. Moreover, the services are found to be integral and essential components of the educational process for all learners as they progress through school. Equally important is the finding that the services, especially consultation and career development offer experiential learning and expose learners to various models of careers of interest to them. Services offering experiential and social learning opportunities help learners in their overall development particularly in their transition to further education and the world of work. The limitation in this study is that the sample from which the data was collected came from a single region of education and this limits its generalizability. Therefore, further research is necessary to explore the perceptions of other stakeholders from other regions.

\section{References:}

1. Alemu, Y. (2013). Assessment of the Provision of Guidance and Counselling services in secondary Schools of East Harenge Zone and Hareri Region, Ethiopia. Middle Eastern \& African Journal of educational Research, (2) 28-37.

2. American school Counselor Association. (2005).The ASCA national model: A framework for school counselling programs $\left(2^{\text {nd }}\right.$ ed.). Alexandria, VA: Author.

3. Babbie, E., \& Mouton, J. (2001). The practice of social research. Cape Town: Oxford University Press.

4. Bardhoshi, G., \& Duncan, K. (2009). Rural school principals' perceptions of the school counselor's role. The Rural Educator, 30(3), 16-24.

5. Bertram, C., \& Christiansen, I. (2014). Understanding research. An introduction to reading research. Pretoria: Van Schaik Publishers. 
6. Borders, L.D., \& Drury, S. M. (1992). Comprehensive school counseling programs: A review for policy makers and practitioners. Journal of Counseling \& Development, 70, 487-498.

7. Chireshe, R. (2011). School Counsellors' and Students Perceptions of the Benefits of School Guidance and Counseling Services in Zimbabwean secondary Schools. College of Education, Department of Further Teacher Education, University of South Africa.

8. Creswell, J.W. (2009). Research design. Mixed methods approaches. ( $3^{\text {rd }}$ edition). London: Sage Publications.

9. du Plooy-Cilliers., Davis, C \& Bezuidenhout, R.M. (2015). Research Matters. Cape Town: Juta \& Company.

10. Education Management Information System (2009), Education Statistics.2008, Windhoek: Namibia.

11. Frank, R.L. (1986). Counselor/administrator perceptions of counselor responsibilities. ERIC Document Reproduction Service (ED 270 705).

12. Gallant, D., \& Zhao, J. (2011). High school students' perceptions of school counselling services: Awareness, Use and Satisfaction. Counseling outcome Research and Evaluation, 2(1), 87-100.

13. Gibson, R., \& Mitchell, M. (2008). Introduction to counseling and guidance. Upper Saddle River, NJ: Prentice-Hall.

14. Gysbers, N. C., \& Henderson, P. (2001). Comprehensive guidance and counseling programs: A rich history and a bright future. Professional School Counseling, 4, 246-256.

15. Lapan, R.T., Gysbers, N.C., \& Petroski, G. (2001). Helping seventh graders be safe and successful: A statewide study of the impact of comprehensive guidance and counseling programs. Journal of Counseling and Development, 79, 320-330.

16. Lapan, R.T., Gysbers, N.C., \& Sun, Y. (1997). The impact of more fully implemented guidance programs on the school experiences of high school students: A statewide evaluation study. Journal of Counselling and Development, 75,292-302.

17. Mbongo, E., Möwes, A., \& Chata, C. (2016). Factors impacting the implementation guidance and counselling services in secondary schools on the Ohangwena region of Namibia. International Journal for Innovation Education and Research, 4(5), 11-25.

18. Mushaandja, J., Haihambo, C., Vergnani, T. \& Frank, E. (2013). Major Challenges Facing Teacher Counsellors in Schools in Namibia. Education Journal. Vol. 2, No. 3, pp. 77-84. doi: 10.11648/j.edu.20130203.13.unenburg, F.C. (2010). School guidance and counseling services. Schooling, 1, 1, 1-9.

19. Myrick, R.D. (2003). Developmental guidance and counseling: A practical approach ( $2^{\text {nd }}$ ed.). Minneapolis: Educational Media. 
20. Namibia Statistics Agency (2015): Annual Report 2015/2016. Namibia Statistics Agency, Windhoek, Namibia.

21. Neuman, W.L. (2011). Social Research Methods: Qualitative and Quantitative Methods. Boston: Pearson.

22. Ninnes, P. (2011). Improving Quality and Equity in Education in Namibia: A trend and Gap Analysis: Presentation to the Ministry of Education, 18 February.

23. Pérusse, R., \& Goodnough, G. E. (2005). Elementary and secondary school counselors' perceptions of graduate preparation programs: A national study. Counselor Education and Supervision, 45, 109-118.

24. Schimmel, C.J. (2008). School counselling in West Virginia. An examination of school counsellors and implementation of West Virginia policy 2315. (Doctoral thesis). Huntington, West Virginia.

25. Schmidt, J. J. (2003). Counseling in Schools: Essential Services and Comprehensive Programs ( $4^{\text {th }}$ ed.) Boston: Pearson Education Inc.

26. Shertzer, B., \& Stone, S. C. (1981). Fundamentals of guidance. $\left(4^{\text {th }}\right.$ ed.). Boston: Houghton Mifflin Company.

27. Stone, L.A.; \& Bradley, F.O. (1994). Foundations of elementary and middle school counseling. Longman: N.Y.

28. Talimenthi, S., \& Mbewa, C.T. (2012). The perception of guidance and counselling to the grade-IX and grade-XII pupils-an investigation of Petauke district schools of eastern province of Zambia. International Multidisciplinary research Journal, 2(7), 13-18.

29. Zalaquett, C. P. (2005). Principals' perceptions of elementary school counselors' role and functions. Professional School Counseling, 8(5), 451-457. 